\title{
Antagonic effect of the inhibition of inducible nitric oxide on the mortality of mice acutely infected with Escherichia coli and Bacteroides fragilis
}

\author{
R.S. Astolfi ${ }^{1}$, D.G. Khouri ${ }^{1}$, \\ L.I.V. Brandizzi², \\ M.J. Ávila-Campos ${ }^{3}$ \\ and H.F. de Andrade Jr. ${ }^{1,4}$
}

\author{
${ }^{1}$ Departamento de Patologia, Faculdade de Medicina, \\ ${ }^{2}$ Laboratório de Biologia Vascular, Instituto do Coração, Hospital das Clínicas, \\ Faculdade de Medicina, \\ ${ }^{3}$ Laboratório de Anaeróbios, Departamento de Microbiologia, \\ Instituto de Ciências Biomédicas, \\ ${ }^{4}$ Laboratório de Protozoologia, Instituto de Medicina Tropical de São Paulo, \\ Universidade de São Paulo, São Paulo, SP, Brasil
}

\author{
Correspondence \\ H.F. de Andrade Jr. \\ Departamento de Patologia \\ Faculdade de Medicina, USP \\ Av. Eneas de Carvalho Aguiar, 470 \\ 05403-000 São Paulo, SP \\ Brasil \\ Fax: +55-11-3088-5237 \\ E-mail: hfandrad@usp.br \\ Research supported by LIM \\ HC-FMUSP-49. R.S. Astolfi was the \\ recipient of an undergraduate \\ fellowship from FAPESP and \\ D.G. Khouri was the recipient of \\ an undergraduate fellowship \\ from CNPq-PIBIC.
}

Received March 20, 2006 Accepted December 1, 2006 $\ldots \ldots \ldots \ldots \ldots \ldots \ldots$

\begin{abstract}
Sepsis, the leading cause of death in intensive care units, is associated with overproduction of nitric oxide (NO) due to inducible NO synthase (iNOS), responsible for some of the pathologic changes. Aminoguanidine $(A G)$ is a selective iNOS inhibitor with reported inconsistent actions in sepsis. To investigate the influence of iNOS, we studied models of acute bacterial sepsis using acute challenges with aerobic (Escherichia coli) and anaerobic (Bacteroides fragilis) bacteria in the presence of AG. Six-week-old, $23 \mathrm{~g}$, male and female BALB/c and $\mathrm{C} 57 \mathrm{Bl} / 6 \mathrm{j}$ mice, in equal proportions, were inoculated (ip) with bacteria in groups of 4 animals for each dose and each experiment in the absence or presence of AG $(50 \mathrm{mg} / \mathrm{kg}$, ip, starting $24 \mathrm{~h}$ before challenge and daily until day 6) and serum nitrate was measured by chemiluminescence. Both types of bacteria were lethal to mice, with an $\mathrm{LD}_{50}$ of 6 nephelometric units (U) for E. coli and $8 \mathrm{U}$ for B. fragilis. Nitrate production peaked on the second day after $E$. coli inoculation with 8 and $6 \mathrm{U}(\mathrm{P}<0.05)$, but was absent after non-lethal lower doses. After challenge with $B$. fragilis this early peak occurred at all tested doses after $24 \mathrm{~h}$, including non-lethal ones $(\mathrm{P}<0.05)$. AG-treated mice challenged with $E$. coli presented higher survival $(\mathrm{P}<0.05)$ and increased $\mathrm{LD}_{50}$. AG-treated mice challenged with $B$. fragilis had lower $\mathrm{LD}_{50}$ and higher mortality. Control AG-treated animals presented no toxic effects. The opposite effect of iNOS blockade by AG in these models could be explained by restriction of oxygen for immune cells or an efficient action of NO in anaerobic localized infections. The antagonic role of $\mathrm{NO}$ production observed in our bacterial models could explain the reported discrepancy of $\mathrm{NO}$ action in sepsis.
\end{abstract}

Key words

- Nitric oxide

- Sepsis

- Experimental model

- Bacterial infections

- Escherichia coli

- Bacteroides fragilis 
Sepsis is the leading cause of death in intensive care units and the third cause of death in developing countries (1), with nitric oxide (NO) acting as an important mediator of its effects, among them hypotension and decreased systemic vascular resistance $(2,3)$. $\mathrm{NO}$ is produced by three different NO synthase (NOS) enzymes, two constitutive ones in endothelial and neural cells and an inducible one (iNOS) produced by immune cells during inflammation (3). The effects of NO in sepsis are attributed to iNOS overproduction, with evidence of a direct relationship between NO levels and sepsis having been obtained in most studies (2,3), although a recent report failed to find a direct association between nitrate levels and tissue perfusion (4).

Selective iNOS inhibitors had a vasopressor effect similar to noradrenaline in animal models of sepsis, with improvement of organ function (5). Aminoguanidine is a relatively selective iNOS inhibitor presenting beneficial effects on septic shock experimentally induced by both Gram-positive (6) and Gram-negative bacteria (7), but has not been tested in anaerobic infection.

In man, the abdomen and pelvis are among the most frequent sites of origin of systemic infections (8), usually induced by trauma or by abdominal surgery with intestinal perforation that leads to the formation of an intraperitoneal abscess by anaerobic bacteria, of which Bacteroides fragilis is the most prevalent species isolated $(9,10)$. Gramnegative bacteria are the leading cause of sepsis in nosocomial infections and Escherichia coli is among the most prevalent agents (10). In addition to the phenotypic differences between agents, there is evidence that the immunological mechanisms of defense against aerobic and anaerobic bacteria are potentially distinct $(11,12)$.

In order to determine the effects of NO overproduction and the consequences of its inhibition on sepsis mortality, we evaluated experimental sepsis induced by $E$. coli or $B$. fragilis in mice, measuring serum nitrate and studying the effect of aminoguanidine on mortality in these models.

Isogenic adult $\mathrm{BALB} / \mathrm{c}$ and $\mathrm{C} 57 \mathrm{Bl} / 6 \mathrm{j}$ mice were maintained in cages in temperature-controlled rooms and received food and water ad libitum. When necessary, the animals were euthanized with $\mathrm{CO}_{2}$. E. coli $\mathrm{DH} 5 \alpha$ strain was grown in TB medium in an orbital shaker, recovered by $5000 \mathrm{~g}$ centrifugation, and washed twice in the same volume of sterile saline, and the concentration in the final suspension was measured by nephelometry at $560 \mathrm{~nm}$ using an Ultrospec UVVisible spectrophotometer (Uppsala, Sweden) with disposable plastic cuvettes. Stock solutions were prepared in saline and adjusted to 100 nephelometric units $(\mathrm{U}) / \mathrm{mL}$ and stored at $-17^{\circ} \mathrm{C}$ until use. Viability was tested in an aliquot grown in TB medium. $B$. fragilis (ATCC 43898) was grown under anaerobic conditions in BHI medium, followed by the same processing and quantification as described above for $E$. coli. A fresh B. fragilis culture was prepared before each experiment. Bacterial count performed by microscopy showed that $1 \mathrm{U}$ corresponded to $4 \times 10^{7}$ bacteria.

Groups of 4 mice received the bacterial challenge intraperitoneally (ip) in a maximum volume of $0.2 \mathrm{~mL}$ containing 1 to $32 \mathrm{U}$ per mice. We used the smallest number of animals in each group which allowed doseresponse estimation in a sigmoidal model on the GraphPad Prism ${ }^{\circledR} 3.0$ software. Mortality measurements were performed to determine the lethal dose $50 \%\left(\mathrm{LD}_{50}\right)$ per animal, which was $6 \mathrm{U}$ for $E$. coli and $8 \mathrm{U}$ for $B$. fragilis. No deaths occurred in groups challenged with less than $2 \mathrm{U}$ for E. coli and $3.125 \mathrm{U}$ for $B$. fragilis. All animals died when challenged with more than $10.5 \mathrm{U}$ for E. coli and $12.5 \mathrm{U}$ for B. fragilis. Data were obtained in at least three independent experiments, with similar results.

The effect of the iNOS inhibitor aminoguanidine was tested in mice challenged 
with three bacterial loads, around the observed $\mathrm{LD}_{50}$, with monitoring of mortality and abscess formation. Aminoguanidine, 50 $\mathrm{mg} / \mathrm{kg}$, was administered ip every day starting $24 \mathrm{~h}$ before the bacterial challenge and maintained until day 6 , at the end of the experiment. This schedule and dosage were based on reported pharmacokinetic studies (13), with a clear interval after starting ip injection before stable steady-state serum levels. Preliminary experiments in which aminoguanidine was administered with the bacterial challenge showed less clear effects (data not shown).

NO production was estimated by serum nitrate concentration. Blood was drawn from retro-orbital veins on the day of inoculation and on the following days. Protein removal was performed as described elsewhere (14). Briefly, serum received two volumes of ethanol at $0^{\circ} \mathrm{C}$, was maintained in an ice bath for $1 \mathrm{~h}$ and centrifuged at 10,000 $\mathrm{g}$ for $1 \mathrm{~min}$ in a Microfuge. The supernatant was stored at $-80^{\circ} \mathrm{C}$ until analysis by chemiluminescence with a Nitric Oxide Analyzer ${ }^{\circledR}$ model 280 from Sievers Instruments ${ }^{\circledR}$ (Boulder, CO, USA).

The survival of animals inoculated with approximately the $\mathrm{LD}_{50}$ of E. coli and $B$. fragilis in presence and absence of the iNOS inhibitor is shown in Figure 1. As expected, there was a positive association between mortality and bacterial concentration in both challenges. Treatment with aminoguanidine instituted $24 \mathrm{~h}$ prior to bacterial inoculation induced a higher short-term survival $(\mathrm{P}=$ 0.048 ) for animals inoculated with $8 \mathrm{U} E$. coli. Mortality was observed only during the first few days. Treatment increased the $\mathrm{LD}_{50}$ of $E$. coli infection, resulting in higher survival of treated mice when sigmoidal curves were compared $(\mathrm{P}<0.02)$. Using the same sigmoidal curve comparison, the opposite effect was observed in the animals challenged with $B$. fragilis, with aminoguanidine-treated animals presenting a worse course, with lower $\mathrm{LD}_{50}(\mathrm{P}<0.01)$. The curves were compared using the Graph Pad
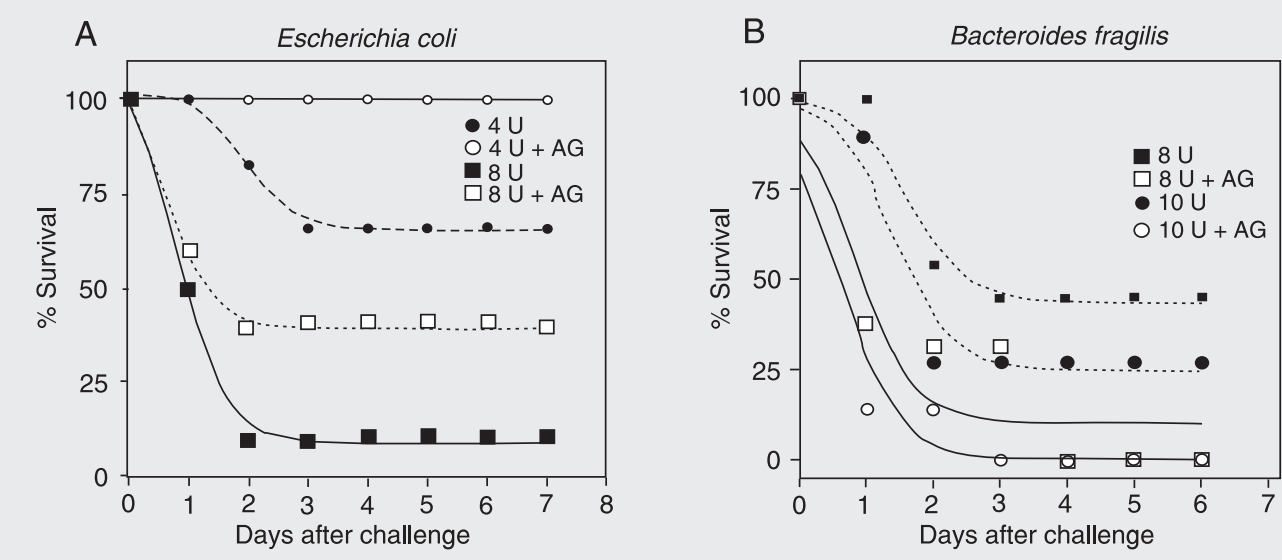

Figure 1. Mouse survival after an intraperitoneal challenge with Escherichia coli (A) and Bacteroides fragilis (B) with and without pretreatment with aminoguanidine. Pretreatment with $50 \mathrm{mg} / \mathrm{kg}$ aminoguanidine (AG) was carried out $24 \mathrm{~h}$ before bacterial inoculation, which occurred on day 0 . Nonlinear regression statistical analysis of the sigmoid dose-response curves showed $9 \%$ survival for animals inoculated with $8 \mathrm{U}$ of $E$. coli $(95 \% \mathrm{Cl}=8.3-11.76)$, and $65.4 \%$ for animals inoculated with $4 \mathrm{U}(95 \% \mathrm{Cl}=63.5-67.3)$, while AG-treated animals inoculated with $8 \mathrm{U}$ had $39.58 \%$ survival $(95 \% \mathrm{Cl}=38.43-40.7)$, and treated animals inoculated with $4 \mathrm{U}$ did not die. Animals inoculated with $10 \mathrm{U}$ and $8 \mathrm{U}$ of $B$. fragilis showed a survival of $24.65 \%(95 \% \mathrm{Cl}=13.5-35.8)$ and $43.68 \%(95 \% \mathrm{Cl}=35.89$ $51.48)$, respectively, while AG-treated animals inoculated with $10 \mathrm{U}$ and $8 \mathrm{U}$ of $B$. fragilis had $2.3 \%(95 \% \mathrm{Cl}=-5.0-$ 9.7 ) and $11 \%$ survival $(95 \% \mathrm{Cl}=9.0-31.8)$, respectively. Mortality was not observed after day 6 in any of the groups. $U=$ nephelometric units. 
Prisma 3.0 software.

Mice challenged with E. coli rapidly developed signs of disease such as bristled hair, adynamic behavior and ocular secretion during the first day following inoculation with lethal doses. The same predictability was not observed for mice challenged with $B$. fragilis, with heterogeneous responses to the same dose. Some animals presented signs of toxemia not followed by death and others die suddenly without signs of toxemia (data not shown).

All animals were killed 10 days after challenge and the abdominal cavity was inspected for the presence of a mass or abscess, and suspected areas were submitted to histopathology. Intraperitoneal abscess formation was observed in $20 \%$ of the surviving animals inoculated with $B$. fragilis, and was absent in all surviving animals inoculated with $E$. coli. Abscesses could be obtained with a single ip inoculation of $8 \mathrm{U} B$.
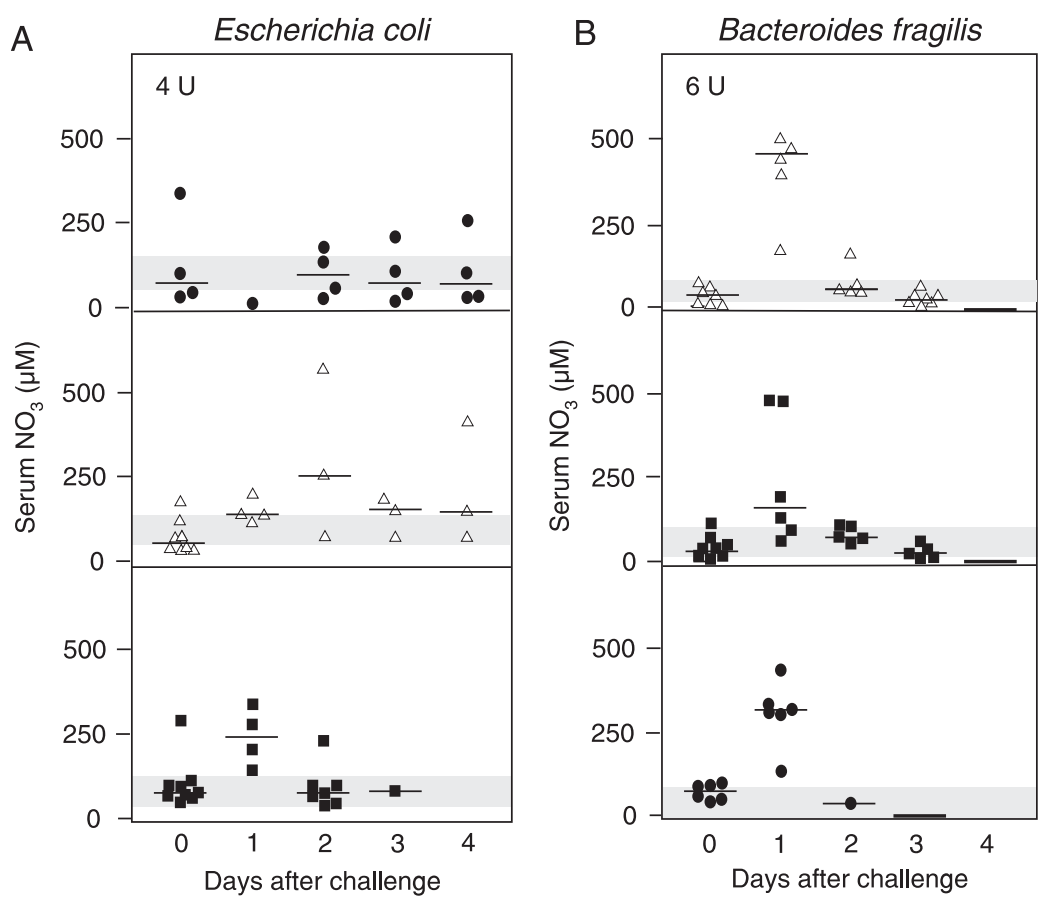

Figure 2. Serum nitrate concentrations of individual mice inoculated with Escherichia coli (A) and Bacteroides fragilis (B). The shaded areas indicate the serum nitrate concentrations of control mice in each experiment and the horizontal bars indicate the mean for each experimental group, with the dose presented in each panel. Day 0 indicates the day of inoculation and basal nitrate. fragilis (data not shown).

Figure 2 shows NO production evaluated on the basis of serum nitrate levels in a typical experiment. Animals inoculated with E. coli showed a peak of NO production $24 \mathrm{~h}$ after inoculation with $8 \mathrm{U}(\mathrm{P}=0.0292)$ and $48 \mathrm{~h}$ after inoculation with $6 \mathrm{U}(\mathrm{P}=0.0496)$, which can be related to the observed mortality. Lower doses failed to produce a significant increase in serum nitrate, without production peaks, a fact probably related to better survival. Mice inoculated with 10, 8 and $6 \mathrm{U}$ of $B$. fragilis presented a peak of nitrate production $24 \mathrm{~h}$ after inoculation $(\mathrm{P}=$ 0.004 for $10 \mathrm{U}, \mathrm{P}=0.0049$ for $8 \mathrm{U}$ and $\mathrm{P}<$ 0.001 for $6 \mathrm{U}$ ), but this peak was not related to the strength of the bacterial challenge.

NO overproduction in patients with sepsis and septic shock has been reported in several studies $(2,15,16)$ and has also been observed in animal models (17), presenting a positive association between serum nitrate and nitrite levels and mortality, as also shown by our $E$. coli inoculation data. This increased mortality was attributed to overproduction of NO and to the systemic inflammatory response, believed to be responsible for vascular hypocontractility, endothelial injury, end-organ damage by free radicals such as peroxynitrite, and myocardial depression, all of which lead to organ ischemia $(2,3)$.

The inhibition of iNOS NO production by aminoguanidine prevents these harmful effects, as also observed in other studies (6, 17). This explains the significant increase in survival with aminoguanidine administration to animals inoculated with E. coli.

$B$. fragilis can form an abscess without association with other bacteria (18). The immunological response leading to abscess formation is stimulated by the $B$. fragilis capsular polysaccharide. This immunological response allows the influx of polymorphonuclear cells into the peritoneal cavity, which is the hallmark of abscess formation (9). In the present experiments, we noticed 
that animals with intraperitoneal abscess formation survived longer than animals that did not form an abscess, when analyzed on the basis of the amount of bacteria inoculated. This result shows the importance of the abscess for host protection, preventing both bacterial dissemination inside the peritoneal cavity and the establishment of a systemic infection.

In the abscess environment the anaerobic conditions do not favor oxidative metabolism, which is responsible for the toxic oxygen-derived products necessary for the oxidative burst, with a consequent need for the activation of oxygen-independent bactericidal mechanisms $(11,12)$. There are reports of a reduction of leukocyte effectiveness in eliminating $E$. coli under aerobic conditions by inhibition of NADPH oxydase, which is responsible for superoxide production. However, no difference was observed when iNOS was inhibited (11), indicating that NO may be a poor bactericidal agent under aerobic conditions. Most reported studies on oxygen-independent alternative mechanisms of bacterial killing under anaerobic conditions relied on enzymes such as the major basic protein, eosinophilic cationic protein and hydrolytic enzymes $(11,12)$, but our experiments do not permit us to speculate about this subject.

Our data suggest that NO must participate directly in the control of anaerobic infections or at least indirectly as an essential mediator of the inflammatory response. NO inhibition probably renders the host's immunological response less effective in restricting bacteria inside the abscess, allowing bacterial dissemination, since surviving animals frequently presented abscesses limited to the abdomen. In a multiple bacterial infection model (19), NO was reported to have an inhibitory effect on neutrophil mi- gration in sepsis, and aminoguanidine treatment was shown to prevent this effect, allowing more effective neutrophil migration and a local action. The present data could also be explained by the use of a specific bacterial agent for challenge, which was much more uniform, but which is also less common in clinical practice, where localized infections are usually caused by multiple organisms.

Aminoguanidine inhibition of NO production can be harmful at higher doses of the inhibitor even in local infections caused by an aerobic agent, since a recent study showed that NO is needed for antibacterial activity in local infections but is associated with decreased survival during Gram-positive bacteremia (20). This paradox could be related to inhibition of endothelial NOS, which occurs at higher doses of aminoguanidine, with reduction of local blood flow and cell migration.

The present data indicate the probable occurrence of several syndromes induced by bacteria, resulting in at least two types of bacterial sepsis according to the oxygen dependence of the agent. This could explain the inconsistent results obtained with the use of iNOS-affecting drugs in sepsis. Our preliminary data suggest that the use of selective iNOS inhibitors as adjuvants for the treatment of sepsis should be considered with caution in each case, according to the type of etiological agent and to the nature of the tissue infection.

\section{Acknowledgments}

We wish to thank Daniel Perez Vieira (IPEN/CNEN/SP), Andres Jimenez Galisteo Jr. (IPEN/CNEN/SP) and Francisco R.M. Laurindo (INCOR) for critical readings of the manuscript and insightful suggestions. 


\section{References}

1. Ulloa L, Tracey KJ. The "cytokine profile": a code for sepsis. Trends Mol Med 2005; 11: 56-63.

2. Doughty L, Carcillo JA, Kaplan S, Janosky J. Plasma nitrite and nitrate concentrations and multiple organ failure in pediatric sepsis. Crit Care Med 1998; 26: 157-162.

3. Murray PT, Wylam ME, Umans JG. Nitric oxide and septic vascular dysfunction. Anesth Analg 2000; 90: 89-101.

4. Dhillon SS, Mahadevan K, Bandi V, Zheng Z, Smith CW, Rumbaut RE. Neutrophils, nitric oxide, and microvascular permeability in severe sepsis. Chest 2005; 128: 1706-1712.

5. Wu CC, Ruetten $\mathrm{H}$, Thiemermann C. Comparison of the effects of aminoguanidine and $\mathrm{N}$ omega-nitro-L-arginine methyl ester on the multiple organ dysfunction caused by endotoxaemia in the rat. Eur $J$ Pharmacol 1996; 300: 99-104.

6. Iskit $A B$, Guc MO. The timing of endothelin and nitric oxide inhibition affects survival in a mice model of septic shock. Eur $J$ Pharmacol 2001; 414: 281-287.

7. Yorganci K, Sayek I, Ismailoglu UB, Sahin-Erdemli I. Detrimental effects of nitric oxide on mesenteric circulation during endotoxaemia and its reversal by aminoguanidine. Eur J Surg 2000; 166: 888-893.

8. Wheeler AP, Bernard GR. Treating patients with severe sepsis. $N$ Engl J Med 1999; 340: 207-214.

9. Gibson FC III, Onderdonk AB, Kasper DL, Tzianabos AO. Cellular mechanism of intraabdominal abscess formation by Bacteroides fragilis. J Immunol 1998; 160: 5000-5006.

10. Kang Cl, Kim SH, Park WB, Lee KD, Kim HB, Kim EC, et al. Bloodstream infections caused by antibiotic-resistant Gram-negative bacilli: risk factors for mortality and impact of inappropriate initial antimicrobial therapy on outcome. Antimicrob Agents Chemother 2005; 49: 760-766.

11. Persson $\mathrm{T}$, Andersson $\mathrm{P}$, Bodelsson M, Laurell M, Malm J, Egesten A. Bactericidal activity of human eosinophilic granulocytes against
Escherichia coli. Infect Immun 2001; 69: 3591-3596.

12. Wetherall BL, Pruul H, McDonald PJ. Oxygen-independent killing of Bacteroides fragilis by granule extracts from human polymorphonuclear leukocytes. Infect Immun 1984; 43: 1080-1084.

13. Bowman MA, Simell OG, Peck AB, Cornelius J, Luchetta R, Look Z et al. Pharmacokinetics of aminoguanidine administration and effects on the diabetes frequency in nonobese diabetic mice. $J$ Pharmacol Exp Ther 1996; 279: 790-794.

14. Alves GM, Barao MA, Odo LN, Nascimento GG, Franco Md Mdo C, Nigro D, et al. L-Arginine effects on blood pressure and renal function of intrauterine restricted rats. Pediatr Nephrol 2002; 17: 856862.

15. Mitaka C, Hirata Y, Yokoyama K, Wakimoto H, Hirokawa M, Nosaka $\mathrm{T}$, et al. Relationships of circulating nitrite/nitrate levels to severity and multiple organ dysfunction syndrome in systemic inflammatory response syndrome. Shock 2003; 19: 305-309.

16. Strand OA, Leone A, Giercksky KE, Kirkeboen KA. Nitric oxide indices in human septic shock. Crit Care Med 2000; 28: 2779-2785.

17. Hayashi Y, Abe M, Murai A, Shimizu N, Okamoto I, Katsuragi T, et al. Comparison of effects of nitric oxide synthase (NOS) inhibitors on plasma nitrite/nitrate levels and tissue NOS activity in septic organs. Microbiol Immunol 2005; 49: 139-147.

18. Shapiro ME, Kasper DL, Zaleznik DF, Spriggs S, Onderdonk AB, Finberg RW. Cellular control of abscess formation: role of $\mathrm{T}$ cells in the regulation of abscesses formed in response to Bacteroides fragilis. J Immunol 1986; 137: 341-346.

19. Benjamim CF, Ferreira SH, Cunha FQ. Role of nitric oxide in the failure of neutrophil migration in sepsis. J Infect Dis 2000; 182: 214223

20. Kerr AR, Wei XQ, Andrew PW, Mitchell TJ. Nitric oxide exerts distinct effects in local and systemic infections with Streptococcus pneumoniae. Microb Pathog 2004; 36: 303-310. 